\section{Reforma do Estado e pesquisa nas telecomunicações no Brasil: um estudo sobre o Centro de Pesquisas e Desenvolvimento- $\mathrm{CPqD}$}

\author{
Fabrício Benedito Menardi \\ Maria Conceição da Costa
}

Revista do

Serviço

Público

Ano 50

Número 2

Abr-Jun 1999

Fabrício B.

Menardi,

mestrando e

Maria Conceição, professoradoutora, ambos do Programa de Pós-Graduação em Política Científica e

Tecnológica da Universidade Estadual de Campinas

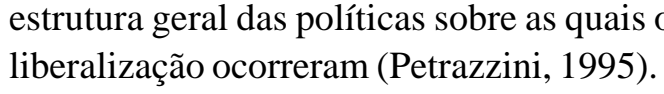

Além do ideário neoliberal, outros fatos podem ser indicados como indutores da necessidade de reordenação das telecomunicações. De acordo com Almeida (1995), existem pressões para a mudança organizacional e institucional do modelo monopolista público que não são exclusivamente de ordem tecnológica (novas tecnologias, serviços e funções das telecomunicações, internacionalização das redes de telecomunicações ${ }^{1}$ e atraso tecnológico do operador), mas vinculam-se a uma teia composta por vários tipos de fatores, onde se incluem: os de natureza econômica (pressão dos grandes usuários), as considerações de ordem sistêmica (resistência à manutenção da rede solidária), bem como os fatores de ordem extra-setorial (crise fiscal e dívida externa, pressão dos órgãos multilaterais ou supranacionais, globalização e regionalização da economia mundial). Note-se que a reformulação dos modelos de regulação setorial nos países avançados, como os países da Comunidade Européia, Estados Unidos e Japão, 
foi uma tentativa de adaptação aos novos modelos de regulação setorial.

Já no caso latino-americano, as pressões para a implementação de políticas de liberalização advêm da crise fiscal e da dívida externa (Almeida).

Além disso, a evolução do aparato tecnológico na economia mundial provoca grandes transformações que, por sua vez, tornam o setor de telecomunicações o elemento central para a rearticulação do sistema capitalista e, assim, promovem o seu desenvolvimento a partir da prática de novas estratégias, de cunho neoliberais, que levam à formação de alianças nacionais e internacionais, seguidas da efetivação da quebra do monopólio público (Leal, 1996).

Em função desse conjunto de pressões supracitado, o setor de telecomunicações, em âmbito mundial, está sendo reordenado. Apesar de essas reformas serem vistas como uma tendência homogênea, uma rápida olhada naqueles países cujas reformas já estão avançadas revela algumas diferenças. Apesar de compartilharem objetivos comuns, esses países seguiram caminhos muito diferentes no processo de mudança organizacional e institucional no setor de telecomunicações. Em particular nas economias em desenvolvimento, verifica-se uma gama de modelos de políticas que cobrem uma complexa e diversa variedade de combinações de formas de propriedade — pública ou privada - e de graus de competição - mercado aberto ou fechado (Petrazzini, 1995).

No Brasil, a estabilidade técnica e institucional do setor de telecomunicação foi substituída por um complexo de opções que combinam a aplicação de tecnologias de informação (tecnologias digitais de transmissão e comutação, incorporação de recursos computacionais às redes) com a introdução de medidas políticas que sinalizam o surgimento de um Estado mais regulador do que produtor.

As décadas de 80 e 90 marcam uma redefinição do papel do Estado, onde os grandes monopólios públicos de serviços de infra-estrutura, denominados “monopólios naturais", são questionados: o Estado deveria retirar-se daqueles setores (comunicações, energia elétrica, transportes), onde a competição poderia ser fomentada pelos mecanismos de mercado, tornando, assim, o sistema regulatório mais eficiente. Sobre essa questão, Milward e Provan (1993) demonstram sua preocupação em relação aos processos de privatizações e utilizam o conceito de "Estado oco" para caracterizar tais processos, apoiados, principalmente, nas limitações de recursos e de capacidade do Estado, sendo que os mesmos não contam com uma análise sobre os custos e benefícios sociais envolvidos.

Na verdade, para além do debate sobre o "Estado mínimo", este Estado adquire, como afirma Maciel e Pessini (1995), "novas responsabilidades, entre elas a de "guiar" o processo de transição, a de redirecionar suas atividades como operador e, sobretudo, a de regular o setor e as condições de concorrência nos diferentes segmentos de mercado". 
Em novembro de 1995, no Brasil, o Presidente da República Fernando Henrique Cardoso aprovou o Plano Diretor de Reforma do Aparelho do Estado que redefine o papel do Estado, deixando este de ser "o responsável direto pelo desenvolvimento econômico e social, pela via da produção de bens e serviços, para se fortalecer na função de promotor e regulador deste desenvolvimento". O objetivo é que o Estado facilite a competitividade internacional da economia brasileira. Todavia, este "novo Estado" não deve retirar-se inteiramente da economia, mas deve, sim, possuir os recursos financeiros e administrativos, i.e., regulatórios, para que, sempre que o mercado não tenha condições de coordenar adequadamente a economia, intervenha de modo efetivo (Bresser Pereira, 1996). Implicitamente, existe a crença que associa uma eficiência cada vez maior do Estado regulador a um papel cada vez maior do mercado ${ }^{2}$. Porém, isso pode implicar uma ampliação e não, como o esperado, uma redução da função de orientação e coordenação do setor privado por parte do Estado, assim como uma capacidade administrativa mais concentrada nas mãos de elites tecnocratas e de administradores públicos (Smiths, 1993).

Bresser Pereira (1993) argumenta em favor de uma recuperação da capacidade de intervenção do Estado. Para o autor, a privatização e a liberalização não podem ser tomadas como um fim em si mesmas. As reformas econômicas devem permitir a definição de um novo modelo de intervenção estatal, onde a restauração da capacidade de investimento público deve ser evidenciada. Seria um equívoco imaginar que o crescimento dos países latino-americanos possa ser retomado apenas com a estabilização e a redução da intervenção do Estado: o tamanho do Estado não constitui um problema em si. A crise dos Estados latino-americanos é a exaustão da intervenção, baseada no modelo de industrialização por substituição de importações, pois a discussão sobre o Estado mínimo não se faz pertinente, e o que subjaz toda a discussão é a crise do Estado. A conclusão só pode ser uma reforma, uma reconstrução do Estado, e não o seu desmonte.

Por outro lado, a reforma do Estado pode ser descrita como uma aplicação do "Consenso de Washington", que se baseia em recomendações básicas, como o crescimento voltado para fora, liberalização, privatização, desregulamentação e equilíbrio fiscal ${ }^{3}$. Admite-se que, se uma vez seguidos esses caminhos, existirá um novo Estado, menor, mais eficiente e mais justo. No entanto, coloca-se a capacidade de governance $^{4}$ do Estado, que define sua condição de sujeito ou objeto nesta ação.

Tavares de Almeida e Moya (1997), em seu estudo sobre as relações entre o Executivo e o Congresso na agenda das privatização das empresas e serviços públicos, sustentam que, para dar início às reformas, o Executivo requereu uma capacidade de insulamento em relação aos grupos interessados na manutenção do status quo. A continuidade do processo, 
afirmam, depende da capacidade deste em mesclar sua independência com

a construção de coalizões de apoio, em função da dinâmica do processo. Mesmo que a autonomia do Executivo não tenha sido um ingrediente significativo no processo político brasileiro nas últimas décadas, o governo não deixou, contudo, de desempenhar o papel principal na definição da agenda das reformas e na sua implementação (Tavares de Almeida e Moya, 1997).

A alta rentabilidade das telecomunicações e o grande valor adicional das empresas colocaram o setor como um dos candidatos prioritários para as privatizações, sobretudo quando o objetivo é a captura de uma receita fiscal de grande magnitude (Costa, 1998). O que se pretende é a recuperação da capacidade de intervenção do Estado por meio da redução de seus problemas de ordem fiscal e financeira ${ }^{5}$.

Com o fim do monopólio estatal nas telecomunicações e a abertura do setor à competição, o braço científico e tecnológico do Sistema Telebrás também foi afetado. Em 23 de julho de 1998, conforme a Lei Geral das Telecomunicações (LGT), o antigo Centro de Pesquisa e Desenvolvimento $(\mathrm{CPqD})$ transformou-se em uma fundação de direito privado, com o nome de Fundação Centro de Pesquisa e Desenvolvimento em Telecomunicações (Fundação CPqD).

O CPqD foi criado em 1976 segundo determinação do Ministério das Comunicações (Minicom), num esforço de reproduzir no Brasil um modelo de centro de pesquisa em telecomunicações que foi gestado nos países desenvolvidos. Seguindo a lógica da cadeia linear e ofertista de inovação, o CPqD foi atrelado ao modelo adotado para o setor de telecomunicações no Brasil, onde o principal objetivo era o desenvolvimento tecnológico setorial, que visava à diminuição da dependência de tecnologia estrangeira, refletindo, assim, uma política de autonomia tecnológica.

\section{O CPqD e as telecomunicações no Brasil}

Foi a partir do início da década de 70, quando se tornou evidente a vulnerabilidade do setor em relação à tecnologia estrangeira, que a Telebrás empenhou-se em desenvolver a capacidade científica, tecnológica e industrial das telecomunicações no Brasil.

Através de uma política fortemente intervencionista, o governo do então presidente Ernesto Geisel definiu uma estratégia industrial e tecnológica para o setor que visava, entre outras coisas, à criação de um centro de P\&D em tecnologia digital, capaz de reduzir a dependência da tecnologia estrangeira e de promover o desenvolvimento da indústria local.

Um centro de P\&D desta natureza era tido como crucial para o estabelecimento de uma política de longo prazo, capaz o bastante para 
fortalecer a base nacional de tecnologia digital, uma vez que, na época, o CPqD era a primeira instituição de acumulação e difusão da tecnologia digital de informação existente no Brasil. De fato, o CPqD tornar-se-ia o principal meio institucional pelo qual a política tecnológica da Telebrás ${ }^{6}$ seria levada a cabo (Hobday, 1990).

Em 31 de agosto de 1976, mediante deliberação da Diretoria da Telebrás e de acordo com o despacho do presidente Ernesto Geisel, baseado em exposição de motivos do Minicom, foi criado o Centro de Pesquisa e Desenvolvimento (CPqD).

$\mathrm{O} \mathrm{CPqD}$ assumiu o papel de coordenação e também a responsabilidade central pelo desenvolvimento de um novo sistema digital, da pesquisa básica, do desenvolvimento e da transferência de tecnologia para a indústria.

\section{Quadro 1: A distribuição da P\&D \\ das atividades em telecomunicações}

\begin{tabular}{ll}
\hline Atividade deP\&D & Grupos responsáveis \\
\hline Pesquisa básica & Universidades e centros de pesquisa \\
Pesquisa aplicada & $\begin{array}{l}\text { Universidades, CPqD e outros } \\
\text { centros de P\&D }\end{array}$ \\
Desenvolvimento de protótipos & CPqD e outros centros de P\&D \\
Desenvolvimento de produtos & $\begin{array}{l}\text { Indústria (eventualmente CPqD e } \\
\text { outros centros de P\&D) }\end{array}$ \\
Desenvolvimento adaptativo & CPqD, outros centros e indústria \\
\hline
\end{tabular}

Fonte: Albuquerque e Waldman (1980, p.3)

Essencialmente, a pesquisa básica era desenvolvida com a universidade, mas sob a coordenação e financiamento da Telebrás. A pesquisa aplicada e o desenvolvimento de protótipos eram conduzidos pelo $\mathrm{CPqD}$, com a opção de se contratar trabalho fora da instituição ${ }^{7}$, se necessário. Em termos de execução da política governamental, o CPqD tinha considerável poder. Ele poderia escolher com qual empresa colaborar na concepção e eventual manufatura dos produtos, e em efeito era capaz de alocar o mercado para as firmas de sua própria escolha. Assim, no seu momento inicial, o CPqD, segundo a legislação ${ }^{8}$, tinha $50 \%$ do mercado futuro dos sistemas desenvolvidos.

A filosofia inicial do CPqD demonstra o papel crucial do governo no setor. $\mathrm{O} \mathrm{CPqD}$ era o meio pelo qual as atividades tecnológicas locais eram identificadas, organizadas, financiadas e expandidas. Pela sua integração na estrutura econômica e industrial, a Telebrás poderia exercer o controle sobre o fornecimento de equipamentos para o setor. Ao mesmo 
tempo, o $\mathrm{CPqD}$ teria como reagir às necessidades do sistema em termos de novos produtos e suporte tecnológico, como o expressado pelas companhias operadoras. Pela sujeição das universidades e dos centros de $\mathrm{P} \& \mathrm{D}$ ao planejamento tecnológico do $\mathrm{CPqD}$, o Brasil deteve a importante decisão sobre a escolha tecnológica, antes facultada somente às empresas estrangeiras (Hobday, 1990).

Num primeiro momento, a escolha tecnológica do CPqD foi determinada pelo objetivo do governo de alcançar a auto-suficiência em tecnologia em telecomunicações e de evitar os custos da escolha obsoleta da tecnologia eletromecânica. Em 1976, as vantagens dos sistemas eletrônicos tornavam-se claras para aqueles que estavam envolvidos com o desenvolvimento das telecomunicações, internacionalmente e no Brasil, e a decisão tomada foi o desenvolvimento de uma gama de sistemas microeletrônicos digitais. Isso requeria um controle da tecnologia nas áreas da transmissão, comutação e equipamento periférico. A idéia, mais tarde cristalizada, era que, assimilando a mais avançada tecnologia digital, o Brasil poderia impedir o alargamento do gap tecnológico nas tecnologias de telecomunicações e possuir uma infra-estrutura em tecnologia de informação. Todavia, no início da década de 80 , os objetivos da política para o setor eram expressados em termos de formação de pessoal e know-how necessário para o desenvolvimento da indústria local e a digitalização total da rede de telecomunicações.

Ao lado dessa estratégia de longo prazo para o domínio da tecnologia digital, o $\mathrm{CPqD}$ respondia às demandas do dia-a-dia das companhias operadoras estatais. As demandas para o desenvolvimento de produtos especiais eram dirigidas ao $\mathrm{CPqD}$ para o desenvolvimento in-house, ou contratados fora. Nesse sentido, o centro alavancava a resposta às necessidades tecnológicas específicas das companhias telefônicas locais. Após o produto estar desenvolvido e o estágio de protótipo alcançado, a tecnologia poderia, então, ser transferida para a indústria, no setor produção. Geralmente as empresas poderiam ser escolhidas antes do estágio da produção, e era necessário para a escolha que esta companhia estivesse ativamente engajada na fase inicial do desenvolvimento. As patentes pertenciam à Telebrás, que poderia então registrar e receber os royalties, normalmente, das companhias operadoras.

A Telebrás investia relativamente pouco em $\mathrm{P} \& \mathrm{D}$, em relação aos seus investimentos totais e à sua receita bruta. A sua política era investir cerca de $1 \%$ das suas receitas operacionais em P\&D, uma taxa muito inferior àquela que as grandes multinacionais esperam investir em $\mathrm{P} \& \mathrm{D}$ internacionalmente. 
Tabela 1: Evolução do orçamento e dos recursos aplicados no CPqD (US\$ milhões)

\begin{tabular}{ccc}
\hline & Investimentos \\
\hline Ano & US\$ & Porcentagem \\
\hline 1986 & 32,2 & $1,56 \%$ \\
\hline 1987 & 36,0 & $1,43 \%$ \\
\hline 1988 & 57,1 & $1,73 \%$ \\
\hline 1989 & 70,6 & $1,45 \%$ \\
\hline 1990 & 72,6 & $1,23 \%$ \\
\hline 1991 & 46,2 & $1,05 \%$ \\
\hline 1992 & 49,0 & $0,92 \%$ \\
\hline 1993 & 86,0 & $1,22 \%$ \\
\hline
\end{tabular}

A estratégia do $\mathrm{CPqD}$ era muito mais permanecer atrás da fronteira tecnológica que se engajar num estado-da-arte da pesquisa, o que permitiria o catch up. $\mathrm{O}$ exame das realizações em termos de programas e projetos sugere que de longe o $\mathrm{CPqD}$ alcançou os objetivos supracitados (Hobday, 1990).

A mudança do paradigma analógico para o digital implicou uma queima de etapas de desenvolvimento, a fim de se atingir estágios tecnológicos semelhantes aos que se encontravam nos países desenvolvidos, e isso foi conseguido com as centrais de comutação digital, por meio do projeto Trópico?.

Por essa época, e em vista dos relativamente baixos recursos alocados para a $\mathrm{P} \& \mathrm{D}, \mathrm{o} \mathrm{CPqD}$ havia adquirido suficientes recursos humanos e infra-estrutura física para gerar uma ampla gama de tecnologias digitais que coordenassem as atividades de outros centros de pesquisa e que transferissem os produtos e processos tecnológicos para a indústria. $\mathrm{E}$, apesar de parecer errado sugerir que esses recursos fossem criados inteiramente pelo $\mathrm{CPqD}$, o centro pôde reivindicar sucesso em organizar, dirigir e ampliar as capacidades tecnológicas para o desenvolvimento das tecnologias digitais. Avanços em projetos tecnológicos e na transferência de patentes para a indústria atestam o dinâmico e o bem-sucedido processo de acumulação tecnológica, não apenas nos sistemas periféricos de transmissão, mas também na complexa área de centrais de comutação e de outras fronteiras tecnológicas, como a fibra óptica e os componentes microeletrônicos (Hobday, 1990). 
A partir da década de 80 , o CPqD passa a sofrer as conseqüências das restrições políticas de combate à inflação que limitava os investimentos e a contratação de pessoal. Nessa fase, o CPqD começa a transferir para o setor industrial a competência e a responsabilidade do desenvolvimento do produto, ficando apenas com o desenvolvimento da tecnologia. Isso se deu como uma forma de redução dos custos de desenvolvimento de protótipos e pela crença de que a indústria já estava capacitada a desenvolver sozinha a tecnologia de produção.

Pelo final dessa década, o CPqD iniciou um processo interno de planejamento estratégico, visando a uma maior competitividade, uma vez que ficou evidenciado que o centro era mais um laboratório de desenvolvimento de produtos para a indústria do que um centro de pesquisa e desenvolvimento e difusão de tecnologia para o setor de telecomunicações. Constatou-se também que, para cumprir essa missão estratégica, o centro precisava estreitar mais os vínculos com as empresas operadoras, por meio de atividades cujos resultados fossem diretamente transferíveis para essas empresas.

Em função da necessidade de mudanças, a instituição definiu um conjunto de diretrizes de atuação que visava ao enxugamento do quadro de pessoal e à adoção de estratégias voltadas para as necessidades do Sistema Telebrás. Assim, o CPqD engajou-se nas atividades de P\&D, por meio da terceirização e do aproveitamento de equipes mistas de universitários e quadros técnicos das indústrias e operadoras.

Com o fim do monopólio estatal nas telecomunicações e início da abertura do setor à competição, o CPqD foi transformado, em julho de 1998, conforme a Lei Geral das Telecomunicações (LGT), em uma fundação privada, sem fins lucrativos, denominada Fundação Centro de Pesquisa e Desenvolvimento em Telecomunicações (Fundação CPqD). A Fundação conta com um Conselho Curador, Diretoria Executiva e Conselho Fiscal. O Conselho Curador é integrado por um representante do Ministério das Comunicações; um do Ministério da Ciência e Tecnologia; um da Financiadora de Estudos e Projetos (FINEP); um do Banco Nacional de Desenvolvimento Econômico e Social (BNDES); dois representantes das operadoras de telecomunicações; dois representantes dos clientes brasileiros da Fundação $\mathrm{CPqD}$; dois da comunidade científica e tecnológica e dois de entidades representativas da sociedade civil.

Tal processo resultou também na criação da Agência Nacional de Telecomunicações (Anatel), que herda do Minicom os poderes, outorgas, regulamentação e fiscalização do setor, bem como a implantação da política nacional de telecomunicações. Contando com um corpo técnico especializado, o $\mathrm{CPqD}$ pode dar apoio à Agência na monitoração do espectro de frequiências e suporte técnico às atividades de regulamentação. 
Outras atividades possíveis ${ }^{10}$ para a atuação da Fundação no novo ambiente estariam na prestação de serviços laboratoriais à indústria (testes de componentes e equipamentos, ensaios laboratoriais, testes de campo, de conformidade e de interfuncionamento para equipamentos), na consultoria e prestação de serviços tecnológicos, treinamento e capacitação tecnológica e na transferência de tecnologia por meio da cobrança de royalties de seus produtos.

Contudo, a principal fonte de receita da Fundação CPqD, neste período de transição, virá através de contratos que visam à prestação de serviços às empresas de telefonia fixa, celular e à Embratel, nas áreas de desenvolvimento tecnológico e de sistemas (softwares), além de prestação de serviços tecnológicos de consultoria e treinamento e serviço laboratorial. Tais contratos, denominados de "Contratos 7000", de valor básico de $\mathrm{R}$ \$124 milhões/ano, proporcionarão a receita para suprir as necessidades orçamentárias básicas da fundação durante três anos.

\section{Observações finais}

Mesmo que o tamanho da planta de telecomunicações brasileira cresça a ponto de alcançar receitas expressivas para garantir os serviços tecnológicos da Fundação, o ideal seria que a Fundação contasse com uma destinação compulsória por parte das receitas das operadoras. $\mathrm{O}$ CNET conta com $4 \%$ da receita da France Télécom, e a NTT Research conta com 4,5\% das receitas das operadoras japonesas. Nos EUA, o Bell Labs seria a exceção, uma vez que pode contar com o poder de compra do Grupo AT\&T, segundo os moldes de financiamento à pesquisa em larga escala que vigora naquele país.

Como uma forma de complementaridade de seus recursos, a Fundação poderia contar com os recursos provenientes do Fundo de Desenvolvimento Tecnológico das Telecomunicações (FDTT), cujo projeto de lei para sua constituição encontra-se, no momento, em tramitação no Congresso Nacional. O FDTT, de acordo com a LGT, teria o objetivo de "estimular a investigação e desenvolvimento de novas tecnologias, incentivar a capacitação de recursos humanos, fomentar a geração de empregos e promover o acesso de pequenas e médias empresas a recursos de capital, de forma a ampliar a competição da indústria de telecomunicações”. De acordo com o item 10.1 da LGT, o FDTT deverá prover parte dos recursos necessários à operação do $\mathrm{CPqD}$, no tocante à manutenção e ampliação de sua infra-estrutura básica de materiais e equipamentos e às pesquisas que servirão de base para desenvolvimentos específicos futuros naquele centro - recursos esses que deverão ser "não-reembolsáveis". 
As receitas do FDTT serão originadas de dotações da lei orçamentária anual e de parcela dos recursos do Fundo de Fiscalização das Telecomunicações (Fistel), os quais são, principalmente, provenientes de taxas de fiscalização da instalação de concessionárias e permissionárias dos serviços de telecomunicações.

O projeto de lei de criação do FDTT prevê como fonte de ingresso uma contribuição de $0,5 \%$ sobre a receita operacional líquida das empresas do Sistema Telebrás, acrescida de uma contribuição de $1 \%$ por parte de dotações previstas na lei de financiamento do Fistel, além de demais doações, rendas e aplicações e empréstimos feitos ao fundo, determinando um patrimônio inicial de R 100 milhões. A aplicação de tais recursos deverá ser a seguinte: $50 \%$ para o BNDES, 30\% para a FINEP/MCT e $20 \%$ para a Fundação CPqD.

As mudanças organizacionais realizadas pelo $\mathrm{CPqD}$, resultado de um novo modelo de Estado - mais regulador que interventor — ainda não estão consolidadas. Mesmo que a estrutura organizacional do CPqD tenha mudado, não houve uma mobilização política em torno da instituição: a extinção da Telebrás deixou a instituição sem um aliado político de peso $^{11}$, a ausência de um senso corporativo das instituições acadêmicas de $P \& D$, principalmente a universidade, não permitiu a formulação de uma estratégia para a defesa do centro. Some-se isto ao fato de a Anatel ter rejeitado a cláusula 15.8 dos contratos de concessão que diz que, em igualdade de condições (preço, prazo e características técnicas), as operadoras deveriam dar preferência, em primeiro lugar, aos produtos fabricados no país, com tecnologia nacional; e em segundo, aos produtos de tecnologia estrangeira fabricados no país. Caso essa cláusula não venha a ser aprovada, tal fato pode ser visto como uma derrota para o setor de fabricantes nacionais e para o $\mathrm{CPqD}$ e favorece o processo de global sourcing das empresas produtoras de equipamentos de telecomunicações no país.

Este trabalho foi uma tentativa de ilustrar a estratégia adotada pelo $\mathrm{CPqD}$ em seu processo de reorganização. Esse processo não envolve somente uma estratégia de mudança técnica ou científica, mas também, e fundamentalmente, uma mudança na forma organizacional. Nesse caso, tais mudanças se deram como uma resposta ao novo desenho do setor de telecomunicações e ao processo de competição instalado após as privatizações. A instituição foi compelida a criar mecanismos que podem resultar em uma maior eficiência e performance: a alocação de recursos entre curto e longo prazo, ou entre demandas imediatas ou potenciais, se tornou uma decisão estratégica central. No entanto, os recursos financeiros provenientes do "Contrato 7000" e que garantem a subsistência "tempo CPqD” estarão disponíveis até o segundo semestre de 2001. Por tudo isso, restam algumas dúvidas em relação à garantia de sustentabilidade de um corpo de atividades de pesquisa desempenhadas por esta instituição. 
${ }^{1} \mathrm{O}$ call-back é o mecanismo mais difundido para a redução de tarifas internacionais. Como assinala Maculan, no segmento de telefonia internacional, a competição baseia-se na redução de custos e, como as chamadas telefônicas têm características de uma commodity, as tarifas mais baixas cobradas por determinada operadora tendem a atrair o tráfego de redes concorrentes.

${ }^{2}$ No entanto, essa situação constitui um paradoxo e coloca um problema prático e conceitual, qual seja, as alterações promovidas nas políticas econômicas, em uma direção menos estática, dependem do Estado como seu promotor.

3 Ainda sobre o "Consenso de Washington", Kaufman acrescenta que, de certa forma, seria um exagero aplicar este conceito às políticas de reforma nos anos $80 \mathrm{e}$ à agenda da reforma do Estado, que tem sido debatida na América Latina. Segundo esse autor, essas mudanças foram influenciadas por "quatro temas desenvolvidos pelo Banco Mundial e outras instituições de financiamento internacional: a) a centralização e o isolamento político do controle sobre a política macroeconômica, particularmente das despesas e decisões monetárias. Nesse contexto, tem sido especialmente enfatizada a delegação de autoridade sobre a política monetária para bancos centrais que não estejam diretamente sujeitos à autoridade constante do Executivo eleito ou do Legislativo; b) a descentralização e/ou privatização da burocracia encarregada da prestação de serviços sociais — pressupondo que as autoridades locais fossem mais sensíveis às demandas de seus eleitores e que a competição entre os fornecedores aumentasse a eficiência dos serviços; c) a delegação de funções reguladoras a agências independentes, encarregadas de supervisionar os prestadores de serviços e de lidar com externalidades associadas à privatização, liberalização do mercado e outras reformas especificamente voltadas para o mercado; d) a criação de quadros mais capacitados de servidores públicos. Eles seriam recrutados de acordo com critérios meritocráticos, teriam autoridade considerável sobre os procedimentos operacionais e seriam avaliados em termos de padrões de desempenho" (Kaufman, 1998).

4 Podemos definir o conceito de governance como a capacidade política do Estado em formular e implementar suas políticas.

5 Com a venda das empresas de telefonia fixa e das empresas que exploram o Serviço Móvel Celular (SMC), o Estado arrecadou um total de R \$22.057 bilhões, com um ágio de $63,76 \%$ sobre o preço mínimo esperado.

6 Desde sua criação, a Telebrás contava em sua estrutura com um Departamento de Pesquisa e Desenvolvimento que, em 1976, "transformou-se" em uma Diretoria de Tecnologia, a qual se subordinou o CPqD.

7 Neste momento, a indústria participava apenas com o fornecimento de recursos humanos, e a Telebrás arcava com todos os custos, inclusive o pagamento de salário dos técnicos cedidos ao $\mathrm{CPqD}$.

8 A Lei no 661 deu à Telebrás o controle sobre o CPqD e instituiu o desenvolvimento, no Brasil, de sua própria família de sistemas de comutação. Inicialmente, $40 \%$ do mercado local foram reservados para a tecnologia produzida pelo CPqD. Mais tarde, a lei oㅡㄴ 15 aumentou essa reserva para 50\%. Esse recurso era uma tentativa deliberada de fortalecer o poder de barganha econômica e tecnológica da Telebrás, em relação às empresas multinacionais.

9 O programa de comutação digital envolve uma família de centrais de comutação pública de programa armazenado, as centrais Trópico. Tais centrais compreendem uma estação concentradora de terminais para pequenas localidades de até 640 assinantes (Trópico 
C); uma estação de pequeno porte, que pode operar com até 20 mil assinantes (Trópico

R) e uma central de médio/grande porte, que pode interligar outras centrais (Trópico RA) ou atender ao serviço local de até 60 mil assinantes (Trópico L). Todas essas centrais encontram-se em operação, representando $19 \%$ da planta de telefonia fixa analógica e $32 \%$ da digital das operadoras de telefonia em todo o país. O projeto Trópico, quando entrou no mercado brasileiro, na década de 80 , diminuiu o custo do terminal telefônico integrado. O projeto era revolucionário, pois engendrava conceitos como o processamento distribuído, que só mais tarde vieram a ser implementados pelas centrais oriundas das grandes empresas estrangeiras.

10 A Fundação criou, junto com a Promom, uma nova empresa, a Trópico S.A., cujo objetivo é desenvolver e fabricar as centrais de telefonia da família Trópico, que atualmente são produzidas pela própria Promom e pela Alcatel — que ficou fora da nova empresa - em vários modelos (Trópico R, RA e L). Já estão instalados cinco milhões de terminais baseados nas centrais Trópico. Uma empresa à parte só para as centrais Trópico era uma questão de sobrevivência, uma vez que as multinacionais devem fazer suas compras seguindo critérios mundiais (RNT, abril de 1999). A trópico S.A. possui 400 funcionários, dos quais 180 estão envolvidos com as áreas de pesquisa e desenvolvimento (90 da Promon, 75 do CPqD e 15 da Alcatel).

11 A Anatel rejeitou a cláusula 15.8 dos contratos de concessão que diz que, em igualdade de condições (preço, prazo e características técnicas), as operadoras deveriam dar preferência, em primeiro lugar, aos produtos fabricados no país, com tecnologia nacional; e em segundo, aos produtos de tecnologia estrangeira fabricado no país, o que põe em perigo a tecnologia local.

\section{Referências bibliográficas}

ABRANCHeS, S. H. H. de. (1996), Reforma regulatória e reforma do Estado: conceitos, experiências e recomendações para o Brasil, mimeo.

Almeida, M. H. T., Moya, M. (1997), A Reforma Negociada: o Congresso e a política de privatização. Revista Brasileira de Ciências Sociais. Vol. 12, $\mathrm{n}^{\circ} 34$.

AlmeIDA, M. W. (1994), Reestruturação, Internacionalização e Mudanças Institucionais das Telecomunicações: Lições de Experiências Internacionais para o Caso Brasileiro. Tese de Doutoramento apresentada ao IE/UNICAMP, São Paulo.

(1995), Concorrência, Privatização e Regulamentação nas Telecomunicações: Desafios e Mito. São Paulo: UNICAMP (mimeo).

Bellini, M. (1994), Desregulamentação de Monopólios Estatais: uma análise do debate em questão". Monografia apresentada ao Instituto de Economia, UNICAMP. Campinas.

Bndes. (1996), Programa Nacional de Desestatização: Relatório de Atividades-1996. Rio de Janeiro.

Bndes. (1997), Brasil: Programas de Privatização. Brasília.

Bresser Pereira, L. C., Maravall, J. M., Przeworski, (1993), A. Reformas econômicas em democracias recentes: uma abordagem social-democrata. Dados, Vol. 36.

Buchanan, J. (1975), Limits of liberty: between anarchy and leviathan. Chicago: The University of Chicago Press.

CoHEn, E. (1992), Le Colbertisme "High Tech". Paris: Hachete. 
Contreras, E. C. A. (1994), Os desbravadores: a Petrobrás e a construção do Brasil industrial. Rio de Janeiro: Relume Dumara.

Costa, M. C. (1991), Telecomunicações no Brasil: A Trajetória de uma Política Tecnológica (1962-1987). IFCH/Unicamp, Dissertação de Mestrado. Campinas. . (1996), Reforma do Estado e Privatização: a resposta para o setor de telecomunicações no Brasil. Texto para Discussão. IGE/Unicamp.

Crozier, M. et Friedberg, E. (1977), "L'acteur et le Système". Editions du Seuil. Paris.

CROZIER, M. (1981), O fenômeno burocrático : ensaio sobre as tendências burocráticas dos sistemas de organização modernas e suas relações na França, com o sistema social e cultural. Brasília, DF : UnB.

. (1998), Como reformar al estado : tres paises, tres estrategias, Suecia, Japon y Estados Unidos. Mexico: Fondo de Cult. Economica.

. (1989), Estado modesto, estado moderno: estratégia para uma outra mudança. Fundação Centro de Formação do Servidor Publico (Funcep). Brasília.

CRUZ, S. V. (1992), Estado e Economia em Tempos de Crise - Política Industrial e Transição Política nos anos 80. Tese de Livre Docência, IFCH, Unicamp.

Dosi, G. (1984), Technical Change and Industrial Transformation. MacMillian. Londres. . (1998), Technical Change and Economic Theory. Londres: Pinter Publishers.

Evans, P. (1992), "The state as problem and solution: predation, embedded autonomy, and structural change" in HAgGard, S., Kaufman, R. R. The politics of economic adjustment: international constraints, distributive conflicts, and the state, USA: Princeton University Press.

Fiori, J. L. (1995), Em Busca do Dissenso Perdido. Rio de Janeiro: Insight Editorial.

FLeURY, M. T. L. \& FisChER, R. M. (org.). Cultura e poder nas organizações. São Paulo: Editora Atlas.

FRISCHTAK, Claudio R. (1995), "The changed role of the state: regulatory policies and reform in a comparative perspective" in FRISCHTAK C. R. (ed.). Regulatory policies and reform: a comparative perspective. Pre-publication edition; The World Bank: Private Sector Department.

Harvey, D. (1993), A Condição Pós-Moderna. São Paulo: Edições Loyola.

HAYEK, Friedrich A. (1990), O caminho da servidão. $5^{\text {a }}$ ed; Rio de Janeiro: Instituto Liberal.

HerReras, A. (1989), La Revolucion Tecnologica y La Telefonia Argentina - De la Unión Telefónica a la Telefónica Argentina. Buenos Aires: Editorial Legasa.

HobDay, M. (1993), "Telecomunications in Developing Countries". The Challenge from Brazil. Londres: Ed. Routlege.

Kaufman, R. (1998), A política da reforma do Estado: um exame de abordagens teóricas. Revista do Serviço Público, ano 49, n. 1, Jan-Mar.

. (1989), "The politics of economic adjustment in Argentina, Brazil and Mexico: experiences in the 1980s and challenges for the future". Policy Sciences, Vol. 22.

Lei Geral das Telecomunicações. (1997) Lei no 9.472. Brasília: Senado Federal.

LindBlon, C. E. (1996), O Processo Decisão Política. Brasília: Editora UnB.

Maculan, A. (1981), Processo decisório no setor de telecomunicações. Dissertação de mestrado - Rio de Janeiro: IUPERJ.

MeAd, G. H. (1964), On social psychology: selected papers. Chicago: Univ. of Chicago Press.

Milward, H. B., Provan, K. G. (1993), "The hollow state: private provision of public services." in Ingram, H, Smith S. R. (ed.). Public policy for democracy. Washington: The Brookings Institution.

OCDE. (1994), Seminário sobre Privatização. São Paulo. 
for Government Policy and Corporate Strategy Development. Berkeley Roundtable on the International Economy/OCDE CEC-DGXIII. Paris: OCDE.

OLson, M. (1982), The rise and decline of nations: economic growth, stagflation, and social rigidities. New Haven and London: Yale University Press.

University Press.

(1965), The logic of collective action. Cambridge, Mass: Harvard

Pinheiro, A. C. (1995), A privatização e os fundos sociais. Conjuntura Econômica, ago.. . (1997), Infra-estrutura, crescimento e a reforma do Estado, mimeo.

PAStoRIZA, F. (1996), Privatização na Indústria de Telecomunicações: Antecedentes e Lições para o caso brasileiro. Texto para Discussão $\mathrm{n}^{\circ} 43$. Rio de Janeiro: BNDES.

Pessini, J. E. \& Maciel, C. S. (1995), "Modelos de Regulação e Políticas Públicas em Telecomunicações". in CoutınHo, L. (org.) Telecomunicações, Globalização e Competitividade. Campinas: Papirus.

Perrow, C. (1972), Análise organizacional: um enfoque sociológico. Atlas. São Paulo.

PIoRE, M. J. and SABEL, C .F. (1984), The Seconde Insdustrial Divide. Basic Books Inc. Publishers. New York.

PIRES, J. C. L. \& PICCINI, M. S. (1997), Serviços de Telecomunicações: aspectos tecnológicos. Ensaios BNDES $n^{\circ}$. 5. Rio de Janeiro: BNDES.

Przeworski, A. (1989), Capitalismo e social - democracia. São Paulo: Cia. das Letras.

SAunders, R., Warford, J. \& Wellenius, B. (1983), Telecomunications and Economic Development. J. Hopkins Univ. Baltimore.

SiqueIra, E. (1993), Telecomunicações - Privatizações ou Caos. São Paulo: TelePress Editora.

SмIтн, W. C. (1993), Reestruturação neoliberal e cenários de consolidação democrática na América Latina. Dados, v. 36, n. 2.

Tavares, M. C. e Fiori, J. L. (1993), Desajuste global e Modernização Conservadora. São Paulo: Ed. Paz e Terra.

Vianna, G. (1993), Privatização das Telecomunicações. Rio de Janeiro: Ed. Notrya.

Wellenius, B. (1989), Restructuring and managing the Telecommunications Sector. Washington, D.C.: World Bank. 


\section{Reforma do Estado e pesquisa nas telecomunicações no Brasil: um estudo sobre o Centro de Pesquisas e Desenvolvimento - CPqD \\ Fabrício Benedito Menardi e Maria Conceição da Costa}

Num cenário de mudanças tecnológicas dinâmicas e num contexto de discussão de Reforma do Estado, o setor de telecomunicações é um locus privilegiado de observação dessas transformações. Partindo dessas duas constatações, este paper analisa o papel do Centro de Pesquisas e Desenvolvimento - CPqD, que nesta última década deixou de ser um centro gerador de tecnologia para se transformar num centro prestador de serviços.

\section{Reforma del Estado y investigación en las telecomunicaciones en Brasil: un estudio sobre el Centro de Investigaciones y Desarrollo - CPqD \\ Fabrício Benedito Menardi y Maria Conceição da Costa}

En un escenario de cambios tecnológicos dinámicos y en un contexto de discusión de reforma del estado, el sector de telecomunicaciones es un locus de observación de esas transformaciones. Partiendo de estas dos constataciones, este artículo analiza el papel del Centro de Pesquisas e Desenvolvimento - $\mathrm{CPqD}$, que en esta última década dejó de ser un centro generador de tecnología para transformarse en un centro de prestación de servicios.

\section{State Reform and research in telecommunications in Brazil: a study on the Centre for Research and Development - CPqD}

Fabrício Benedito Menardi and Maria Conceição da Costa

The sector of telecommunications is a priviledged locus for the observation of the changes taking place both in the organization of the state and in the technological dynamics. Having this in mind, this paper analyses the Centro de Pesquisas e Desenvolvimento (Centre for Research and Developmentin Telecommunication) which, recently, has become much more concerned with technological services and trouble shouting than in developing research and development activities properly.
Revista do

Serviço

Público

Ano 50

Número 2

Abr-Jun 1999
Fabrício B.

Menardi, mestrando e Maria Conceição, professoradoutora, ambos do Programa de Pós-Graduação em Política Científica e Tecnológica da Universidade Estadual de Campinas 